\title{
Subchronic Phencyclidine Administration Reduces Mesoprefrontal Dopamine Utilization and Impairs Prefrontal Cortical-Dependent Cognition in the Rat
}

\author{
J. David Jentsch, B.A., Anh Tran, B.A., Dung Le, B.A., Kenneth D. Youngren, M. Phil., \\ and Robert H. Roth, Ph.D.
}

Repeated ingestion of phencyclidine by humans induces enduring schizophrenic symptomatology, particularly cognitive dysfunction. In the presently described series of experiments, the neurochemical and cognitive consequences of subchronic phencyclidine administration in the rat were explored. Repeated phencyclidine exposure led to a selective reduction in basal and stress-evoked dopamine utilization in the prefrontal cortex. In addition, rats previously subchronically-treated with phencyclidine were impaired on performance of a spatial working memory task in a delaydependent manner. Importantly, these dopaminergic and cognitive deficits were observed after withdrawal from phencyclidine, and as such, the neurochemical and behavioral effects were due to drug-induced neurobiological changes rather than direct drug effects. These biochemical and behavioral data show that repeated phencyclidine administration induces prefrontal cortical cognitive deficits in rats, as in humans, and offer a biochemical perspective of the neural substrate underlying this cognitive impairment: inhibition of mesocortical dopamine neurons. Thus, these data may have relevance to psychiatric disorders involving prefrontal cortical dopaminergic hypoactivity and cognitive dysfunction, as has been hypothesized in schizophrenia.

[Neuropsychopharmacology 17:92-99, 1997]

(C) 1997 American College of Neuropsychopharmacology. Published by Elsevier Science Inc.
KEY WORDS: Cognition; Dopamine; Phencyclidine; Prefrontal cortex; Psychotomimetic; Rat; Working memory; Schizophrenia; Utilization

Several lines of research suggest that schizophrenia may involve dysfunction of the prefrontal cortex, and possibly, its dopaminergic innervation (reviewed in Carlsson 1988; Goldman-Rakic 1991; Kahn and Davis 1995). The prefrontal cortex receives a prominent dopa-

From the Section of Neurobiology, the Interdepartmental Neuroscience Program, and Departments of Pharmacology and Psychiatry, Yale University School of Medicine, New Haven, Connecticut.

Address correspondence to: Robert H. Roth, Ph.D., Department of Pharmacology, Yale University School of Medicine, P.O. Box 208066, New Haven, Connecticut 06520-8066.

Received January 6, 1997; revised February 13, 1997; accepted February 17, 1997. mine projection (Thierry et al. 1973; Williams and Goldman-Rakic 1993), and dopamine appears to be a critical neuromodulatory influence on the cognitive functions of this region, particularly working memory. Regionally-restricted dopamine depletion or dopamine receptor blockade can impair performance of working memory tasks in monkeys (Brozoski et al. 1979; Sawaguchi and Goldman-Rakic 1991) and rats (Bubser and Schmidt 1990). In addition, increased dopamine transmission in the prefrontal cortex, induced by a pharmacological stressor, can impair spatial working memory (Murphy et al. 1996), possibly by degrading memory-related firing of prefrontal cortical neurons (Williams and Goldman-Rakic 1995).

Prefrontal cortical cognitive dysfunction, including working memory deficits, have been demonstrated in 
schizophrenia (Fey 1951; Goldman-Rakic 1991; Park and Holzman 1992; Goldberg and Gold 1995), and these deficits may be related to a dopaminergic dysfunction, which has been hypothesized to be involved in schizophrenia (Carlsson 1988; Davis et al. 1990; Robbins 1990; Grace 1991; Deutch 1992). Evidence in support of dopamine dysfunction in schizophrenia include the high affinity of most typical antipsychotic drugs for the dopamine D2 receptor (Seeman 1992; Deutch et al. 1992) and the activation of dopaminergic transmission by acute administration of such psychotomimetic drugs as amphetamine (During et al. 1987), cocaine (Sorg and Kalivas 1993), $\Delta^{9}$-tetrahydrocannabinol (Bowers and Morton 1994) and phencyclidine (PCP; Deutch et al. 1987; Bowers and Morton 1994; Hondo et al. 1994; Hertel et al. 1996; Jentsch et al. 1997).

Given acutely, PCP and the PCP congener, ketamine, induce hyperactivity, paranoia, hallucinations, formal thought disorder and cognitive impairments in normal human subjects (Luby et al. 1959; Davies and Beech 1960; Pearlson 1981; Javitt and Zukin 1991; Krystal et al. 1994; Malhotra et al. 1996). Cognitive deficits have also been observed in PCP- or ketamine-treated rats (Danysz et al. 1988; Alessandri et al. 1989; Verma and Moghaddam 1996) and monkeys (Boyce et al. 1991). The cognitive dysfunction induced by acute PCP or ketamine challenge may be mediated by increased dopamine release and utilization in the prefrontal cortex as hyperdopaminergic states of the prefrontal cortex are correlated with impaired spatial working memory (Murphy et al. 1996; Verma and Moghaddam 1996).

Repeated exposure to PCP can more reliably induce robust and enduring cognitive deficits in humans (Pearlson 1981; Cosgrove and Newell 1991). The development of a profound and enduring psychotomimetic reaction after repeated PCP exposure suggests that long-lasting neurobiological changes which mimic some features of the neuroetiology of schizophrenia may occur.

Schizophrenic subjects have been shown to have a failure of metabolic activation of frontal cortical regions during performance of prefrontal-dependent tasks (Ingvar and Franzen 1974; Weinberger et al. 1986, 1988; Weinberger and Berman 1996), and this effect is similarly observed in PCP-abusing humans (Hertzman et al. 1990; Wu et al. 1991). Interestingly, the hypofrontality associated with schizophrenia may be related to a dopaminergic dysfunction (Weinberger et al. 1988; Dolan et al. 1995).

Whereas acute PCP administration activates dopamine systems, contributing to a hyperdopaminergic hypothesis of schizophrenia, the neurochemical effects of repeated PCP exposure remain unexplored. In the present set of experiments, the neurochemical and cognitive consequences of subchronic PCP administration in the rodent were characterized. Specifically, whether repeated exposure to PCP alters prefrontal cortical dopamine and cognitive function was investigated. The present evidence suggests that subchronic PCP administration induces a selective prefrontal cortical dopaminergic deficit and an associated cognitive dysfunction.

\section{METHODS}

\section{Animals}

Male Sprague-Dawley CAMM rats (Charles River Labs, Portage, MI) were used as subjects. The rats were maintained on a 12-hour light-dark cycle with the light phase being 7:00 A.M. to 7:00 P.M. Rats used for biochemical studies were fed and watered ad libitum, while those used for cognitive testing were food-restricted for the duration of the experiment to maximize the palatability of food rewards used in the cognitive testing. Animals performing the cognitive task were fed approximately $5 \mathrm{~g}$ of food a day immediately following testing; water was always available in the home cage.

\section{Drugs}

Phencyclidine hydrochloride (Research Biochemicals Inc., Natick, MA) was dissolved in sterile saline and injected at $1 \mathrm{ml} / \mathrm{kg}$ intraperitoneally (i.p.). Drug weights were calculated as the salt.

\section{Studies of Basal Neurotransmitter Metabolism}

In experiments studying basal utilization, animals were subchronically treated with either saline $(1 \mathrm{ml} / \mathrm{kg}$ once or twice a day for 7 or 14 days) or PCP $(10 \mathrm{mg} / \mathrm{kg}$ once a day for 7 to 14 days, or $5 \mathrm{mg} / \mathrm{kg}$ twice a day for 7 days). Twenty-four hours after the final treatment, they were removed from their home cage and sacrificed. No intermediate challenge or stressor was delivered.

\section{Stress Experiment}

In some studies, rats were challenged with a mild footshock stress after receiving subchronic treatments. Animals were subchronically treated with either oncea-day injections of saline $(1 \mathrm{ml} / \mathrm{kg})$ or PCP $(10 \mathrm{mg} / \mathrm{kg})$ for 14 days, and 1 or 2 days after the final administration, they were placed in standard grid-floor shock boxes illuminated with red-light. Background noises were masked with white noise broadcast in the chamber. Either no shock (sham) or shock (10 random 0.5 second $0.3 \mathrm{~mA}$ shocks over 20 minutes) was delivered. This regimen was chosen to selectively activate dopamine utilization in the prefrontal cortex. Rats were sacrificed immediately following the stress session. Shock boxes were cleaned with $70 \%$ ETOH between rats to remove olfactory cues. 


\section{Biochemistry}

All rats weighed $250-275 \mathrm{~g}$ at the time of sacrifice. Sacrifices were performed during the animals' light phase. Rats were euthanized by rapid decapitation, their brains were quickly removed, and brain regions were dissected out on a chilled platform. Samples were immediately frozen on dry ice and stored at $-70^{\circ} \mathrm{C}$ until assayed.

Tissues were prepared using dihydroxybenzylamine as an internal control. Samples were homogenized in $400 \mu$ l of ice-cold $0.1 \mathrm{M}$ perchloric acid and centrifuged at $46000 \mathrm{~g}, 200 \mu \mathrm{l}$ of the supernatant was analyzed directly with HPLC using electrochemical detection with a glassy carbon electrode at $+0.7 \mathrm{~V}$ (BAS, West Lafayette, IN) and a reversed-phase column ( $3 \mu \mathrm{m} \mathrm{C18}$ beads, $100 \AA$ diameter, $10 \mathrm{~cm}$ length; BAS, West Lafayette, IN). Pellets were analyzed for protein content according to Lowry et al. (1951). The remaining $200 \mu \mathrm{l}$ of supernate was processed for levels of 3-methoxy-4hydroxyphenylglycol (MHPG; free + conjugate) by mass spectrometry/gas chromatography according to Elsworth et al. (1983).

Mobile phase used for HPLC was an $8 \%$ solution of acetonitrile containing $0.6 \%$ tetrahydrofuran, $0.1 \%$ diethylamine, $0.025 \mathrm{mM}$ EDTA, $2.3 \mathrm{mM}$ 1-octane-sulfonic acid, $30 \mathrm{mM}$ sodium citrate and $13.7 \mathrm{mM}$ sodium dihydrogen phosphate (final pH 3.1).

Measurements of utilization were made as the ratio of tissue concentration (in $\mathrm{ng} / \mathrm{mg}$ protein) of the primary metabolite, dihydroxy-O-phenylacetic acid (DOPAC) or MHPG to the parent amine (dopamine or norepinephrine, respectively).

\section{Cognitive Testing}

Rats were tested 5 days a week during the light phase by an experienced tester who tested the rats at the same time every day to preclude circadian effects. The individual rat testers were always blind to any drug treatments.

As noted above, all rats were food-restricted for the duration of the experiment; each rat was fed approximately $5 \mathrm{~g}$ of rat chow immediately after testing each day. No rat experienced weight loss during the experiment; in fact, all rats gained $5-10 \%$ of their body weight each week until they reached their adult weights of 450-500 g. Highly palatable miniature chocolate chips were used as a reward during testing.

White noise was broadcast in the testing room during daily experiments to prevent external noises from disturbing performance of the task. A standard black T-maze was used for delayed alternation testing.

\section{Delayed Alternation Testing}

Training and testing was performed with modification of the methods described previously in Murphy et al.
(1996). In the present experiment, a variable-delayed alternation was utilized in order to construct delay functions for each rat. After a rat had been trained, it began testing under a single-delay condition. This delay was increased until the animal stabilized at $80 \%$ performance for 3 days. Then a delay curve was constructed by presenting the animal with five separate delays spanning from ' 0 ' sec (as a control) to twice the duration of their current delay (e.g., 0, 20, 40,60, $80 \mathrm{sec}$ ) over a 20-trial session (each delay encountered 4 times throughout the session). This variable-delay task was administered for two days. Then, the animal received oncea-day subchronic saline $(1 \mathrm{ml} / \mathrm{kg})$ or PCP $(10 \mathrm{mg} / \mathrm{kg})$ injections for 14 days. Two days after the final injections, performance under the 20-trial variable-delay task was reassessed. Following reassessment, the rats continued to be tested under the variable-delay conditions; however, no rat was studied in the cognitive paradigm more than 10 days after cessation of PCP treatments.

\section{Statistics}

For biochemical and cognitive studies, group comparisons were performed with one-way analysis of variance (ANOVA) followed by Scheffe's F-test for post-hoc analysis. Comparisons of stress responsivity in saline- and PCP-treated animals utilized two-way ANOVA (with drug and shock conditions as factors) followed by appropriate post-hoc tests. Analyses were performed with Statview II (Abacus Concepts, Berkeley, CA) on a Macintosh IIcx. All data is presented as mean \pm S.E.M.

\section{RESULTS}

\section{Basal Monoamine Utilization after Subchronic PCP Treatment}

Basal dopamine utilization (as assessed by the ratio of tissue levels of DOPAC to dopamine) in the prefrontal cortex was significantly reduced 24 hour after the last injection of PCP when $10 \mathrm{mg} / \mathrm{kg}$ once a day for 14 days $\left(74.3 \pm 5.8 \%\right.$ of control; $\left.\mathrm{F}_{(1,7)}=8.7 ; \mathrm{p} \leq .05\right)$ and $5 \mathrm{mg} /$ $\mathrm{kg}$ twice a day for 7 days $\left(66.8 \pm 5.2 \%\right.$ of control; $F_{(1,15)}=$ 9.9; $\mathrm{p} \leq 0.01$ ) but not $10 \mathrm{mg} / \mathrm{kg}$ once a day for 7 days $\left(95.8 \pm 9.4 \%\right.$ of control; $\left.F_{(1,15)}=0.1 ; p>.05\right)$ was administered (Figure 1). None of these treatment regimens significantly altered basal dopamine utilization in the nucleus accumbens or dorsolateral striatum (Figure 1). Importantly, all changes in dopamine utilization are metabolite driven, as no significant effect of subchronic PCP administration on absolute dopamine levels was detected (Table 1). In addition, no difference in basal norepinephrine (MHPG/norepinephrine) metabolism was detected in the prefrontal cortex of rats subchronically treated with saline versus PCP $(123.3 \pm 13.2 \%$ of control; $\left.\mathrm{F}_{(1,7)}=2.1 ; \mathrm{p}>.05\right)$. 


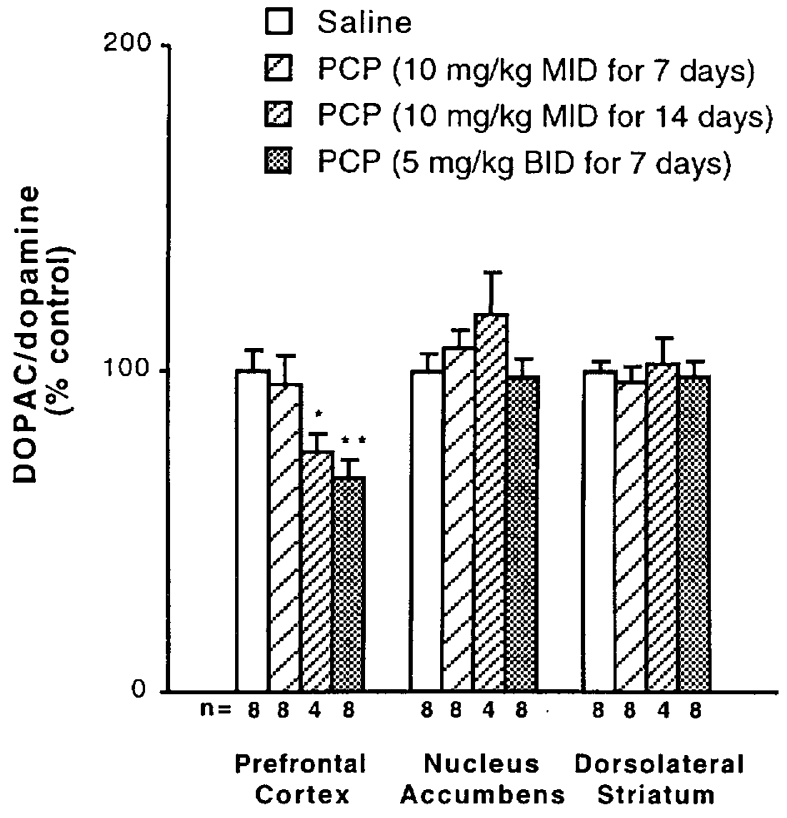

Figure 1. Subchronic exposure to PCP reduces basal dopamine utilization in the prefrontal cortex, but not subcortical regions of the rat brain. Twice a day administration appears to better induce the inhibition. Data represent mean \pm SEM. Significantly reduced relative to saline-treated controls: ${ }^{*} \mathrm{p} \leq .05 ;{ }^{* *} \mathrm{p} \leq .01$.

\section{Stress-Evoked Dopamine Metabolism in Prefrontal Cortex after Subchronic PCP Treatment}

In order to further investigate the nature of the PCP-induced prefrontal cortical dopaminergic dysfunction, animals previously subchronically treated with either PCP or saline were challenged with mild foot-shock, a stressor which evokes increased dopamine release and turnover in the prefrontal cortex of normal animals. Subjects were treated once a day for 14 days with saline or PCP $(10 \mathrm{mg} / \mathrm{kg})$, stressed 24 or $48 \mathrm{hrs}$ after the final drug administration and sacrificed immediately following the stress session. No differences between the 24 and 48

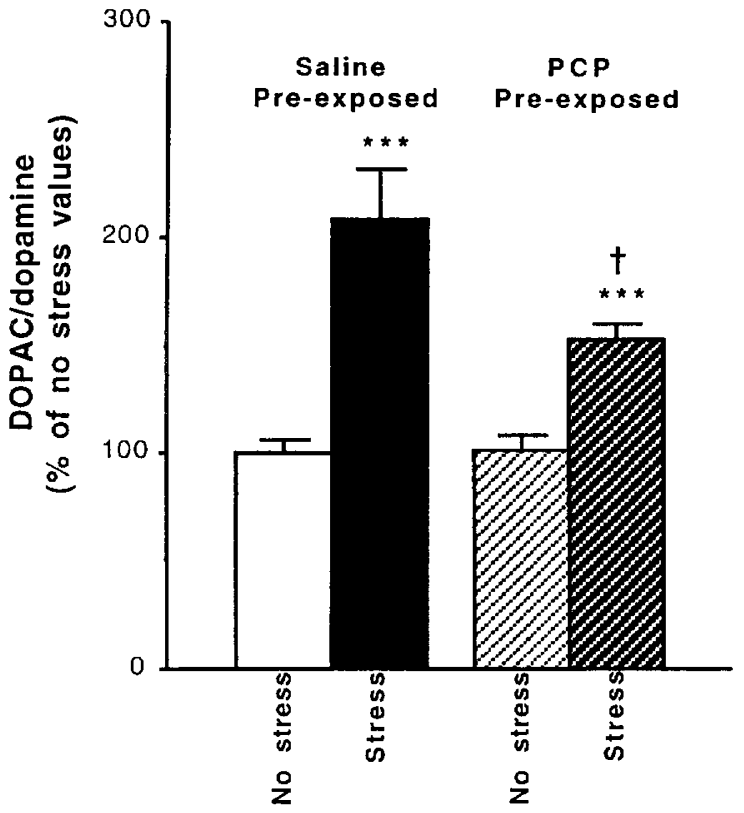

Figure 2. A mild foot-shock stress increases dopamine utilization in the prefrontal cortex of both saline- and PCPtreated controls; however, the response of the mesocortical dopamine system (assessed as the \% increase relative to no stress values) is reduced in PCP-pre-exposed animals relative to saline-treated controls. The absolute DOPAC/dopamine ratios are: saline $/$ no stress $=0.27 \pm 0.02$, saline $/$ stress $=$ $0.57 \pm 0.07, \mathrm{PCP} /$ no stress $=0.23 \pm 0.01, \mathrm{PCP} /$ stress $=0.35 \pm$ 0.02 . Data represent mean \pm SEM. $n=8$ for all observations. ** Significantly increased relative to no stress values: $p \leq$ .001 . TSignificantly reduced relative to saline-pre-exposed/ stress values: $\mathrm{p} \leq .05$.

hour post-drug groups were measured, so these data were combined for analysis.

Animals subchronically treated with saline responded to the stress with an increase in dopamine utilization to $208.0 \pm 23.1 \%$ of control (saline-preexposed/no stress) levels (Figure 2; $F_{(1,15)}=20.3 ; p \leq .001$ ). In addition, PCP-pretreated animals exhibited a significant stressinduced activation of frontal cortical dopamine metabo-

Table 1. Dopamine Levels in Rat Brain Are Unchanged After Repeated PCP Administration

\begin{tabular}{|c|c|c|c|c|}
\hline & Saline & $\begin{array}{l}\text { PCP (10 mg/kg } \\
\text { MID for } 7 \text { days) }\end{array}$ & $\begin{array}{l}\text { PCP }(10 \mathrm{mg} / \mathrm{kg} \\
\text { MID for } 14 \text { days })\end{array}$ & $\begin{array}{c}\text { PCP }(5 \mathrm{mg} / \mathrm{kg} \text { BID } \\
\text { for } 7 \text { days) }\end{array}$ \\
\hline Prefrontal cortex & $\begin{array}{c}00.43 \pm 0.06 \\
(n=12)\end{array}$ & $\begin{array}{c}00.32 \pm 0.03^{a} \\
(\mathrm{n}=8)\end{array}$ & $\begin{array}{c}00.60 \pm 0.03^{b} \\
(\mathrm{n}=4)\end{array}$ & $\begin{array}{c}00.36 \pm 0.03 \\
(n=8)\end{array}$ \\
\hline Nucleus accumbens & $\begin{array}{c}38.68 \pm 4.28 \\
(\mathrm{n}=12)\end{array}$ & $\begin{array}{c}28.94 \pm 2.16 \\
(\mathrm{n}=8)\end{array}$ & $\begin{array}{c}53.18 \pm 6.74 \\
(n=4)\end{array}$ & $\begin{array}{c}33.34 \pm 4.03 \\
(\mathrm{n}=8)\end{array}$ \\
\hline Dorsolateral striatum & $\begin{array}{c}79.61 \pm 3.64 \\
(\mathrm{n}=12)\end{array}$ & $\begin{array}{c}76.71 \pm 4.57 \\
(\mathrm{n}=8)\end{array}$ & $\begin{array}{c}75.05 \pm 8.73 \\
(n=4)\end{array}$ & $\begin{array}{c}80.76 \pm 5.18 \\
(n=8)\end{array}$ \\
\hline
\end{tabular}

No difference in basal dopamine levels ( $\mathrm{ng} / \mathrm{mg}$ protein) in saline- and PCP-treated animals indicate that all observed changes in dopamine utilization are metabolite driven. Data represent mean \pm SEM.

"Not significantly different: $\mathrm{F}_{(1,18)}=2.27 ; \mathrm{p}=.15$.

${ }^{b}$ Not significantly different: $F_{(1,14)}=2.25 ; \mathrm{p}=.153$. 
Table 2. Stress Fails to Alter Dopamine Levels in Saline- or PCP-Treated Rat Prefrontal Cortex

\begin{tabular}{lll}
\hline & No Shock & Shock \\
\hline Saline pre-exposed & $0.53 \pm 0.06$ & $0.46 \pm 0.08$ \\
PCP pre-exposed & $0.56 \pm 0.05$ & $0.50 \pm 0.04$ \\
\hline
\end{tabular}

No difference in basal dopamine levels ( $\mathrm{ng} / \mathrm{mg}$ protein) due to salineor PCP-treatment or to no shock/shock condition in the prefrontal cortex of the rat. Data represent mean \pm SEM. $\mathrm{n}=8$ for all measures.

lism (Figure 2; $152.7 \pm 7.9 \%$ of PCP-preexposed/no stress values, $\left.\mathrm{F}_{(1,15)}=22.1 ; \mathrm{p} \leq .001\right)$. However, the response to an acute stressor (calculated as the \% increase in dopamine utilization after stress relative to no stress condition) was significantly reduced in PCP-preexposed animals relative to saline-exposed animals (i.e., there was a significant interaction between drug treatment and no-shock/shock condition: $\mathrm{F}_{(1,28)}=4.6 ; \mathrm{p}<$ $.05)$. These effects were metabolite driven as no changes in basal dopamine values were induced by PCP or shock condition (Table 2). No increase in nucleus accumbens dopamine utilization in either saline- or PCPpretreated animals was observed at the shock intensity used in this study (data not shown).

\section{Cognitive Effects of Subchronic PCP Exposure}

Before drug treatment, no significant differences in choice accuracy were detected between the saline-treated and PCP-treated groups $\left(\mathrm{F}_{(1,11)}=0.7 ; \mathrm{p}>.05\right)$; however a delay-dependent reduction in accuracy was observed across both groups $\left(\mathrm{F}_{(4,29)}=4.3 ; \mathrm{p} \leq .01\right)$. Subchronic PCP exposure led to impairments of performance on a spatial delayed alternation task, relative to salinetreated controls $\left(\mathrm{F}_{(1,11)}=2.7 ; \mathrm{p} \leq .05\right)$, and this impairment was delay-dependent $\left(\mathrm{F}_{(4,29)}=11.5\right.$; $\left.\mathrm{p}<.001\right)$, i.e., impairments were evident at longer delays, with no deficits at the ' 0 ' sec delay condition (Figure 3).

\section{DISCUSSION}

The results of the present series of experiments demonstrate that repeated exposure to PCP leads to an inhibition of basal and stress-evoked dopamine utilization in the prefrontal cortex of the rat. These changes in responsivity are not accompanied by a change in absolute dopamine concentrations, suggesting that an anatomical lesion of the dopaminergic innervation does not occur after repeated PCP exposure. In addition, norepinephrine utilization in the prefrontal cortex and dopamine utilization in other brain regions were not different in salineand PCP-pre-exposed animals, suggesting that the reduction in dopamine utilization in the prefrontal cortex is not as a result of generalized alterations in catecholamine metabolism. Thus, it appears that the reduction in prefrontal cortical dopamine utilization is indicative of a reduced activity of mesoprefrontal dopamine neurons, i.e., a partial functional lesion of the mesocortical dopamine projection in rats.

\section{Cognitive Correlates of Dopaminergic Dysfunction}

The prefrontal cortex and its dopaminergic innervation are involved in working memory processes in rodents and primates (Goldman-Rakic 1987). Prefrontal cortical

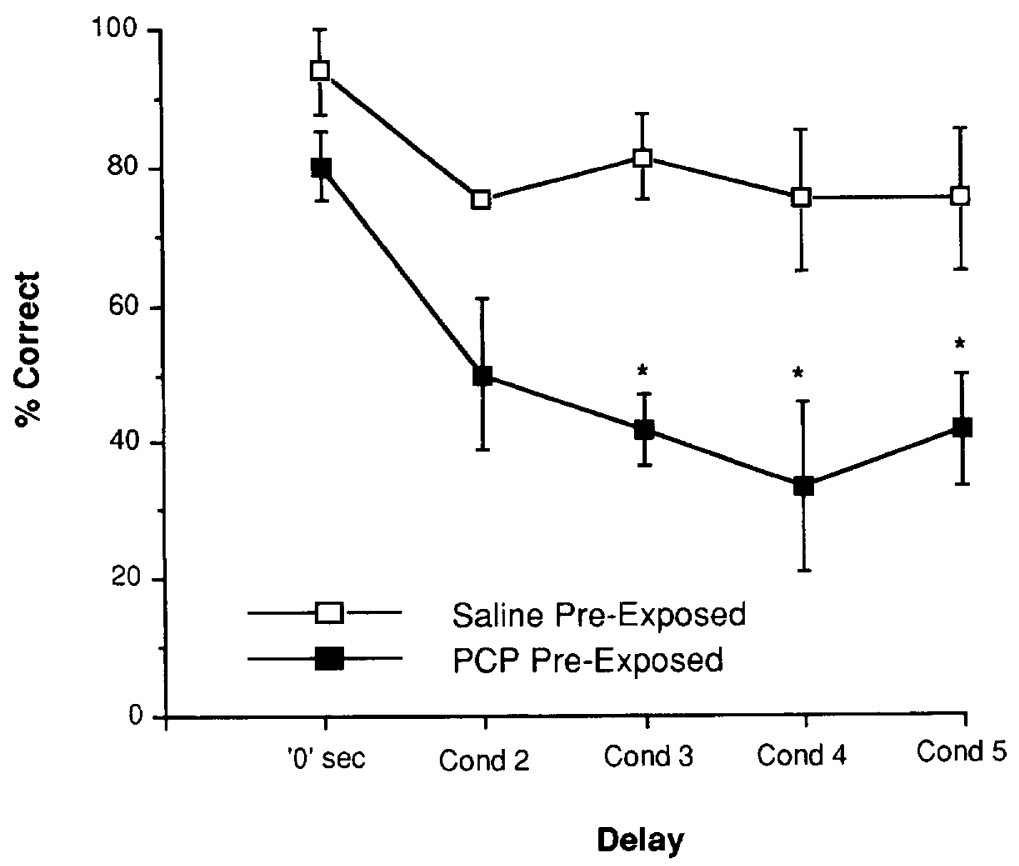

Figure 3. Rats subchronically exposed to PCP have delay-dependent working memory impairments relative to saline-treated controls as assessed by performance of a delayed alternation task. Data represent mean \pm SEM. $n=6$ for all observations. * Significantly impaired relative to saline-treated controls: $\mathrm{p} \leq .05$. 
ablation in monkeys (Goldman et al. 1971), regionallyspecific destruction of dopamine terminals in the prefrontal cortex of rats and monkeys with 6-hydroxydopamine (Brozoski et al. 1979; Bubser and Schmidt 1990) and local prefrontal cortical dopamine D1 receptor blockade (Sawaguchi and Goldman-Rakic 1991) all induce performance deficits on tasks dependent on working memory. We thus hypothesized that the subchronic PCP-induced reduction in dopaminergic utilization in the frontal cortex would be accompanied by a working memory deficit. This hypothesis was confirmed, as rats subchronically treated with PCP exhibited performance impairments on spatial delayed alternation, a task dependent on intact working memory function. These deficits were delay-dependent, suggesting that the performance impairments were due to a cognitive, and not a non-specific, dysfunction.

\section{Selective Inhibition of the Mesocortical Dopamine Projection}

Subchronic PCP administration exerts preferential, if not selective, effects on the mesocortical dopamine innervation. In contrast to the depression of dopamine utilization in the prefrontal cortex, no such effect was observed in other dopamine-rich forebrain sites, such as the dorsolateral striatum or nucleus accumbens. In addition, no changes in norepinephrine turnover were measured in the medial prefrontal cortex after repeated PCP exposure. These data are consistent with previous findings regarding the selective pharmacological modulation of the prefrontal cortical dopamine projection (Deutch and Roth 1990).

\section{Relevance to Subcortical Dopmaine Systems}

Recent work suggests that the prefrontal cortex exerts potent regulatory effects over the mesolimbic and nigrostriatal dopamine systems (Deutch 1992; Murase et al. 1993; Taber and Fibiger 1993, 1995). The dopaminergic innervation of the prefrontal cortex appears to have an inhibitory influence on subcortical dopamine systems, i.e., reductions in prefrontal cortical dopamine levels result in heightened activation of mesolimbic dopamine neurons by stress or haloperidol in the rat (Deutch et al. 1990; Rosin et al. 1992) or increased high K+-evoked dopamine release in the marmoset caudate nucleus (Roberts et al. 1994), whereas augmentation of extracellular dopamine levels in prefrontal cortex, with local amphetamine or cocaine application, reduces dopamine release in the caudate of the monkey (Kolachana et al. 1995). Thus, subchronic PCP-induced inhibition of frontal cortical dopamine function may be associated with a heightened activity of subcortical structures. This hypothesis awaits further experimentation; however, preliminary evidence suggests that subchronic PCP-treated rats, un- der the present treatment regimen, are hyperresponsive to the locomotor-stimulating effects of amphetamine (unpublished observations), possibly indicating a heightened mesolimbic response to amphetamine.

\section{Relevance to Schizophrenia}

Whereas early studies of the acute effects of psychostimulants like PCP contributed to a hyperdopaminergic hypothesis of schizophrenia, more recent data have suggested that cortical dopaminergic hypoactivity (underlying cognitive deficits and some other negative symptoms of schizophrenia) and subcortical dopamine hyperactivity (underlying some positive symptoms of schizophrenia) may be involved in the disorder. Negative symptoms, including but not limited to cognitive deficits, appear to be unaffected by typical antipsychotic drugs (Lee et al. 1994), which possess potent dopamine D2 receptor antagonist properties (Seeman 1992; Deutch et al. 1992). Direct or indirect dopamine receptor agonists such as amphetamine (Angrist et al. 1982; van Kammen and Boronow 1988; Daniel et al. 1991) and apomorphine (Daniel et al. 1989; Dolan et al. 1995) may ameliorate hypofrontality or negative symptoms in schizophrenia, while exacerbating positive symptoms (Angrist and Gerson 1970, 1977; Angrist et al. 1980). Also, schizophrenic subjects exhibit deficits on Wisconsin Card Sort performance and failure of task-related activation of the dorsolateral prefrontal cortex, and these deficits are inversely correlated with cerebrospinal fluid homovanillic acid levels (Weinberger et al. 1986, 1988), suggesting that central dopaminergic deficits may be involved in the cognitive deficits. Finally, reduced dopaminergic innervation of the prefrontal cortex has been shown in schizophrenia (Akil and Lewis 1996). Thus, the prefrontal cortical dopaminergic hypofunction and cognitive deficits induced by repeated PCP administration may more successfully model a cortical dopaminergic and cognitive deficit in schizophrenia.

\section{ACKNOWLEDGMENTS}

We thank Kristina Kudelko for her reliable technical assistance. Supported in part by USPHS grant \#MH14092 (RHR) and the Scottish Rite Schizophrenia Research Program, N.M.J., U.S.A. (JDJ). Portions of these data were presented in abstract form: Jentsch JD and Roth RH (1996): Differential effects of acute and repeated phencyclidine exposure on prefrontal cortical dopamine: relevance to schizophrenia. Soc Neurosci Abstr 22:1320.

\section{REFERENCES}

Akil M, Lewis DA (1996): Reduced dopamine innervation of the prefrontal cortex in schizophrenia. Soc Neurosci Abstr 22:1679 
Alessandri B, Battig K, Welzl H (1989): Effects of ketamine on tunnel maze and water maze performance in the rat. Behav Neural Biol 52:194-212

Angrist BM, Gershon S (1970): The phenomenology of experimentally-induced amphetamine psychosis: Preliminary observations. Biol Psychiatry 2:95-107

Angrist B, Gershon S (1977): Clinical response to several dopamine agonists in schizophrenic and nonschizophrenic subjects. Adv Biochem Pharmacol 16:667-680

Angrist B, Rotrosen J, Gershon S (1980): Differential effects of amphetamine and neuroleptics on negative versus positive symptoms in schizophrenia. Psychopharmacol 72: 17-19

Angrist B, Peselow E, Rubenstein M, Corwin J, Rotrosen J (1982): Partial improvement in negative schizophrenic symptoms after amphetamine. Psychopharmacol 78: $128-130$

Bowers MB, Morton JB (1994): Regional brain catecholamines and metabolites following THC, PCP and MK801. Prog Neuro-Psychopharmacol \& Biol Psychiat 18: 961-964

Boyce S, Rupniak NMJ, Steventon MJ, Cook G, Iversen SD (1991): Psychomotor activity and cognitive disruption attributable to NMDA, but not stigma, interactions in primates. Behav Brain Res 42:115-121

Brozoski TJ, Brown RM, Rosvold HE, Goldman PS (1979): Cognitive deficit caused by regional depletion of dopamine in prefrontal cortex of rhesus monkey. Science 205:929-931

Bubser M, Schmidt WJ (1990): 6-OHDA lesions of the rat prefrontal cortex increases locomotor activity, impairs acquisition of delayed alternation tasks, but does not affect uninterrupted tasks in the radial maze. Beh Brain Res 37:157-168

Carlsson A (1988): The current status of the dopamine hypothesis of schizophrenia. Neuropsychopharmacol 20:379-382

Cosgrove J, Newell TG (1991): Recovery of neuropsychological functions during reduction in use of phencyclidine. J Clin Psychol 47:159-169

Daniel DG, Berman KF, Weinberger DR (1989): The effect of apomorphine on regional cerebral blood flow in schizophrenia. J Neuropsychiatry 1:377-384

Daniel DG, Weinberger DR, Jones DW, Zigun JR, Coppola R, Handel S, Bigelow LB, Goldberg TE, Berman KF, Kleinman JE (1991): The effect of amphetamine on regional cerebral blood flow during cognitive activation in schizophrenia. J Neurosci 11:1907-1917

Danysz W, Wroblewski JT, Costa E (1988): Learning impairment in rats by $\mathrm{N}$-methyl-D-aspartate receptor antagonists. Neuropharmacol 27:653-656

Davies BM, Beech HL (1960): The effect of 1-arylcyclohexylamine (Sernyl) on twelve normal volunteers. J Ment Sci 106:912-924.

Davis KL, Kahn RS, Ko G, Davidson M (1991): Dopamine in schizophrenia: a review and reconceptualization. Am J Psychiatry 148:1474-1486

Deutch AY (1992): The regulation of subcortical dopamine systems by the prefrontal cortex: interactions of central dopamine systems and the pathogenesis of schizophrenia. J Neural Transm suppl 36:61-89
Deutch AY, Clark WA, Roth RH (1990): Prefrontal cortical dopamine depletion enhances the responsiveness of mesolimbic dopamine neurons to stress. Brain Res 521: 311-315

Deutch AY, Moghaddam B, Innis RB, Krystal JH, Aghajanian GK, Bunney BS, Charney DS (1991): Mechanisms of action of atypical antipsychotic drugs: Implications for novel therapeutic strategies for schizophrenia. Schizophr Res 4:121-156

Deutch AY, Roth RH (1990): The determinants of stressinduced activation of the prefrontal cortical dopamine system. In Vylings HBM, Eden CGV, DeBruim JPC, Corner MA, Feenstra MGP (eds), The Prefrontal Cortex: Its Structure, Function and Pathology. Amsterdam, Elsevier, pp. 367-403

Deutch AY, Tam SY, Freeman AS, Bowers MB, Roth RH (1987): Mesolimbic and mesocortical dopamine activation induced by phencyclidine: contrasting pattern to striatal response. Eur J Pharmacol 134:257-264

Dolan RJ, Fletcher P, Frith CD, Friston KI, Frackowiak RSJ, Grasby PM (1995): Dopaminergic modulation of impaired cognitive activation in the anterior cingulate cortex in schizophrenia. Nature 378:180-182

During MJ, Bean AJ, Roth RH (1992): Effects of CNS stimulants on the in vivo release of the colocalized transmitters, dopamine and neurotensin, from rat prefrontal cortex. Neurosci Lett 140:129-133

Elsworth JD, Roth RH, Redmond DE (1983): Relative importance of 3-methoxy-4-hydroxyphenylglycol and 3,4dihydroxyphenylglycol as norepinephrine metabolites in rat, monkey and human. J Neurochem 41:786-793

Fey ET (1951): The performance of young schizophrenics and young normals on the Wisconsin Card Scoring Test. J Consult Psychol 15:311-319

Goldberg TE, Gold JM (1995): Neurocognitive functioning in patients with schizophrenia. In Bloom FE, Kupfer DJ (eds), Psychopharmacology: the Fourth Generation of Progress. New York, Raven Press, pp. 1245-1257

Goldman PS, Rosvold HE, Vest B, Gallan TW (1971): Analysis of the delayed-alternation deficit produced by dorsolateral prefrontal lesions in the rhesus monkey. J Comp Phys Psych 77:212-220

Goldman-Rakic PS (1987): Circuitry of the frontal cortex and the regulation of behavior by representational knowledge. In Plum F, Mountcastle V (eds), Handbook of Physiology, Vol. V, The Nervous System. Bethesda, American Physiological Society, pp. 373-417

Goldman-Rakic PS (1991): Prefrontal cortical dysfunction in schizophrenia: The relevance of working memory. In Carroll BJ, Barrett JE (eds), Psychopathology and the Brain. New York, Raven Press, Ltd., pp. 1-23

Grace AA (1991): Phasic versus tonic dopamine release and the modulation of dopamine system responsivity: a hypothesis for the etiology of schizophrenia. Neurosci 41:1-24

Hertel P, Mathe JM, Nomikos GG, Iurlo M, Mathe AA, Svensson TH (1996): Effects of D-amphetamine and phencyclidine on behavior and extracellular concentrations of neurotension and dopamine in the ventral striatum and the medial prefrontal cortex of the rat. Behav Brain Res 72:103-114 
Hertzman M, Reba RC, Kotlyarove EV (1990): Single photon emission computerized tomography in phencyclidine and related drug abuse. Am J Psychiatry 147:255-256

Hondo $\mathrm{H}$, Yonezawa $\mathrm{Y}$, Nakahara $\mathrm{T}$, Nakamura K, Hirano M, Uchimura H, Tashiro N (1994): Effect of phencyclidine on dopamine release in the rat prefrontal cortex; an in vivo microdialysis study. Brain Res 633:337-342

Ingvar DH, Franzen G (1974): Distribution of cerebral activity in chronic schizophrenia. Lancet 2:1484-1486

Javitt DC, Zukin SR (1991): Recent advances in the phencyclidine model of schizophrenia. Am J Psychiatry 148: 1301-1308

Jentsch JD, Elsworth JD, Redmond DE, Roth RH (1997): Phencyclidine increases forebrain monoamine metabolism in rats and monkeys: Modulation by the isomers of HA966. J Neurosci, 17:1769-1776.

Kahn RS, Davis KL (1995): New developments in dopamine and schizophrenia. In Bloom FE, Kupfer DJ (eds), Psychopharmacology: The Fourth Generation of Progress. New York, Raven Press, pp. 1193-1204

Kolachana BS, Saunders RC, Weinberger DR (1995): Augmentation of prefrontal cortical monoaminergic activity inhibits dopamine release in the caudate nucleus: an in vivo neurochemical assessment in the rhesus monkey. Neurosci 69:859-868

Krystal JH, Karper LP, Seibyl JP, Freeman GK, Delaney R, Bremner JD, Heninger GR, Bowers MB, Charney DS (1994): Subanesthetic effects of the nocompetitive NMDA antagonist, ketamine, in humans: psychotomimetic, perceptual, cognitive and neuroendocrine responses. Arch Gen Psychiatry 51:199-214

Lee MA, Thompson PA, Meltzer HY (1994): Effects of clozapine on cognitive function in schizophrenia. J Clin Psychiatry 55 suppl B:82-87

Lowry OH, Rosebrough NJ, Farr AL, Randall RJ (1951): Protein measurement with the folin phenol reagent. J Biol Chem 193:265-275

Luby ED, Cohen BD, Rosenbaum G, Gottlieb JS, Kelly R (1959): Study of a new schizophrenomimetic drugSeernyl. Arch Neurol Psychiatry 81:363-369

Malhotra AK, Pinals DA, Weingartner H, Sirocco K, Missar CD, Pickar D, Breier A (1996): NMDA receptor function and human cognition: the effects of ketamine in healthy volunteers. Neuropsychopharmacol 14:301-307

Murase S, Grenhoff I, Chouvet G, Gonon F, Svensson TH (1993): Prefrontal cortex regulates burst firing and transmitter release in rat mesolimbic dopamine neurons studied in vitro. Neurosci Lett 157:53-56

Murphy BL, Arnsten AFT, Goldman-Rakic PS, Roth RH (1996): Increased dopamine turnover in the prefrontal cortex impairs spatial working memory performance in rats and monkeys. Proc Natl Acad Sci USA 93:1325-1329

Park S, Holzman PS (1992): Schizophrenics show spatial working memory deficits. Arch Gen Psychiatry 49:975-982

Pearlson GD (1981): Psychiatric and medical syndromes associated with phencyclidine (PCP) abuse. The Johns Hopkins Med J 148:25-33

Roberts AC, De Salvia MA, Wilkinson LS, Collins P, Muir JL,
Everitt BJ, Robbins TW (1994): 6-hydroxydopamine lesions of the prefrontal cortex in monkeys enhance performance on an analogue of the Wisconsin Card Sort Test: possible interactions with subcortical dopamine. J Neurosci 14:2531-2544.

Robbins TW (1990: The case for frontostriatal dysfunction in schizophrenia. Schizophr Bull 16:391-402.

Rosin DL, Clark WA, Goldstein M, Roth RH, Deutch AY (1992): Effects of 6-hydroxydopamine lesions of the prefrontal cortex on tyrosine hydroxylase activity in subcortical dopamine systems in the rat. Neurosci 48:831-839.

Sawaguchi T, Goldman-Rakic PS (1991): D1 dopamine receptors in prefrontal cortex: involvement in working memory. Science $251: 947-950$.

Seeman P (1992): Dopamine receptor sequences. Therapeutic levels of neuroleptics occupy D2 receptors, clozapine occupies D4. Neuropsychopharmacol 7:261-284.

Sorg BA, Kalivas PW (1993): Effect of cocaine and footshock stress on extracellular dopamine levels in the medial prefrontal cortex. Neurosci 53:695-703.

Taber MT, Fibiger HC (1993): Electrical stimulation of the medial prefrontal cortex increases dopamine release in the striatum. Neuropsychopharmacol 9:271-275

Taber MT, Fibiger HC (1995): Electric stimulation of the prefrontal cortex increases dopamine release in the nucleus accumbens of the rat: modulation by metabotropic glutamate receptors. J Neurosci 15:3896-3904

Thierry AM, Blanc G, Sobel A, Stinus L, Glowinski J (1973): Dopaminergic terminals in the rat cortex. Science 182: 499-501

van Kammen DP, Boronow JJ (1988): Dextro-amphetamine diminishes negative symptoms in schizophrenia. Psychopharmacol 3:111-121

Verma A, Moghaddam B (1996): NMDA receptor antagonists impair prefrontal cortical function as assessed via spatial delayed alternation performance in rats: modulation by dopamine. J Neurosci 16:373-379

Weinberger DR, Berman KF, Zec RF (1986): Physiologic dysfunction of dorsolateral prefrontal cortex in schizophrenia: I. Regional cerebral blood flow evidence. Arch Gen Psychiatry 43:114-125

Weinberger DR, Berman KR, Illowsky BP (1988): Physiologic dysfunction of dorsolateral prefrontal cortex in schizophrenia. III. A new cohort and evidence for a monoaminergic mechanism. Arch Gen Psychiatry 45:609-615

Weinberger DR, Berman KF (1996): Prefrontal function in schizophrenia: confounds and controversies. Phil Trans R Soc Lond B 351:1495-1503

Williams GV, Goldman-Rakic (1995): Modulation of memory fields by dopamine D1 receptors in prefrontal cortex. Nature 376:572-575

Williams SM, Goldman-Rakic (1993): Characterization of the dopaminergic innervation of the primate frontal cortex using a dopamine-specific antibody. Cerebral Cortex 3:199-222

Wu JC, Buchsbaum MS, Bunney WE (1991): Positron emission tomography study of phencyclidine users as a possible drug model of schizophrenia. Jpn J Psychopharmacol 11:47-48 